\title{
PYLORIC STENOSIS IN TWINS
}

\author{
BY \\ B. W. POWELL and C. O. CARTER \\ From The Hospital for Sick Children, Great Ormond Street, London
}

(Received for Plblication April 14, 1950)

In 1938 Sheldon analysed 1,000 cases of hypertrophic pyloric stenosis and found 23 pairs of twins of which one or both had been affected. In this series one pair was monozygous and 12 dizygous. The type of twinning in the remaining pairs could not be decided. The evidence indicated that when pyloric stenosis affects monozygous twins both infants show the condition, but that when the twins are dizygous only one of the pair is likely to be affected. He recorded, in addition, one exception to this rule, namely, monozygous twins, only one of which was affected. The only previously recorded exception was by Lasch (1925). In this case no tumour was felt during life, and according to Sheldon the description of the post-mortem appearance of the pylorus left some doubt as to whether the condition was in fact hypertrophic stenosis.

In 1947 Laubscher and Smith reviewed 53 pairs of twins collected from the literature (including Sheldon's series) and found only one more exception, a dizygous pair both of which were affected. They found in all two exceptions in 13 monozygous pairs and one exception in 23 dizygous pairs. Since then two further exceptions to the rule have been reported. Garrison (1949) reported a pair of monozygous twins only one of which was affected, and Hughes, Small, and Macky (1949) reported a dizygous pair with both twins affected. There have been published six further examples of pyloric stenosis in twins which conform to the rule. Lamy, Pognan, Marillier, Jammet, and Cordier (1949) reported a monozygous pair in which both twins were affected. Dizygous pairs with one affected (three pairs) have been recorded by Cockayne and Penrose (1943), and one pair by Ward-McQuaid and Porritt (1950).

The purpose of this paper is to discuss the occurrence of the condition among monozygous and dizygous twins and to report four further pairs, all of which were exceptions to the rule mentioned above. In considering these cases it is obvious that two important questions must be answered: Is pyloric stenosis present in one or both of the pair ? Are the twins monozygous or dizygous? In the majority of cases it is possible to give the answers with reasonable certainty. Sometimes, as the cases reported here will show, it may prove difficult. The problems presented by these questions will be briefly discussed before the cases are described.

\section{The Diagnosis of Pyloric Stenosis}

A positive diagnosis is usually easy, and the classical symptoms and signs are well-known. Moreover, since the treatment nowadays is nearly always surgical, an opportunity is given for confirming the presence of a pyloric tumour beyond all doubt.

It is more difficult to exclude the condition when the classical features are absent or present in a very mild degree. Wallgren (1937), Findlay (1937), Bexelius (1939), Malmberg (1939), and Lewis (1944) have published cases in which the anatomical deformity was present without symptoms, or in which the symptoms were mild and recovery spontaneous. One of the cases reported here was also symptom-free. Davison (1946) used the term 'manifest' pyloric stenosis to distinguish the typical cases from the symptom-free ones, and considered that the latter occur infrequently. There is, however, no evidence to show how often they do occur, for the condition might well escape notice unless it were specially looked for.

The observation of gastric peristalsis does not by itself justify the diagnosis, but palpation of a pyloric tumour is unequivocal. Radiology may be useful in doubtful cases (Miller and Ostrum, 1945; Olnick and Weens, 1949), although Wallgren (1946) has shown that in the preclinical stage radiological appearances may be normal in infants who later develop manifest pyloric stenosis.

It may not be possible or justifiable to subject an apparently healthy infant to repeated examinations, but it is suggested that the investigation should be as thorough as possible before the diagnosis of pyloric stenosis is excluded. This applies particularly when the condition appears in one of a pair of twins. 


\section{Determination of Type of Twinning}

The problem of stating with any degree of certainty whether twins are monozygous or dizygous may also present some difficulty. Ford, Brown, and McCreary (1941) pointed out that the determination of the type of twinning in published cases is often inadequate. The conclusion is based on the sex, birth membranes, physical resemblance and blood groups, but in many reports the evidence is scanty and few details are given. The description of the placenta may be misleading, as information is often incomplete and a detailed examination is usually not made at the time of birth. It is possible for monozygous twins to have separate placentas and for dizygous twins to have their placentas fused so as to appear single. A comparison of physical characters is difficult in infancy, particularly when the progress of one twin has been interrupted by illness.

\section{Case Histories}

Family 1. Monozygous twins, one affected. Born July 12, 1948. Second pregnancy (one stillbirth previously). No family history of pyloric stenosis. Parents not consanguineous.

TwIN A. Boy. Birth weight $5 \mathrm{lb} .6 \mathrm{oz}$. Bottle fed since 2 weeks old. Sudden onset of projectile vomiting when 37 days old, followed by constipation and loss of weight. Admitted nine days later. Gastric peristalsis was seen, a pyloric tumour was felt, and at operation a typical pyloric tumour was discovered.

TwIN B. Boy. Birth weight $5 \mathrm{lb} .5 \mathrm{oz}$. Bottle fed since 2 weeks of age. Thrived and gained weight normally. There was an occasional regurgitation of feeds during the sixth week, but never any vomiting. Admitted to hospital with his twin, and during the eight days under observation no abnormality was detected. He was examined for the presence of peristalsis or a tumour, but neither was found.

The twins were seen again at 3 months of age and at 1 year and both were progressing normally. Twin B had remained free from symptoms.

Family 2. Monozygous twins, one affected. Born April 20, 1949. Fourth pregnancy (one boy, 9 years old, and one girl, 6 years, both well: abortion 18 months previously). No family history of pyloric stenosis. Parents not consanguineous.

TwIN A. Boy. Birth weight $7 \mathrm{lb}$. Bottle fed. Projectile vomiting associated with constipation began when 21 days old. Admitted to hospital two weeks later. Gastric peristalsis was seen and a pyloric tumour felt. At operation a small pyloric tumour was found. For three days the infant did well, but post-operative complications occurred and he died three weeks later. At necropsy the presence of a pyloric tumour was confirmed.

TwIN B. Boy. Birth weight $7 \mathrm{lb}$. Bottle fed. Thrived and gained weight normally, with no vomiting or constipation. He was examined during feeds on two occasions (aged 41 and 58 days) and no peristalsis or tumour was detected. On the second occasion a barium meal was given but no abnormality could be seen. At two hours the bulk of the meal was in the small intestine, and at three hours only a few flecks were left in the stomach. At 10 weeks old his own doctor reported that he was still free from symptoms.

Family 3. Dizygous twins, both affected (one symptom-free). Born May 13, 1949. Third pregancy (one boy, died at birth with ' deformed head,' one girl, 18 months old, well). No family history of pyloric stenosis. Parents not consanguineous.

Twin A. Boy. Birth weight $6 \mathrm{lb} .8 \mathrm{oz}$. Bottle fed. Sudden onset of projectile vomiting when 19 days old. On admission five days later gastric peristalsis was seen and a pyloric tumour felt. At operation a small hard tumour was found. Recovery was uneventful.

TwIN B. Boy. Birth weight $6 \mathrm{lb} .8 \mathrm{oz}$. Bottle fed. He thrived and gained weight normally with no vomiting or constipation. First examined aged 32 days when peristalsis was clearly seen during a feed, but no tumour could be felt. A barium meal was given the same day and vigorous gastric peristalsis was seen, but no other abnormality detected. The stomach was empty of barium in two and a half hours. The infant was examined again when 51 days old, and on this occasion a small pyloric tumour was felt by several experienced observers. He was last seen at 6 months old and had remained free from symptoms.

Family 4. Monozygous twins, one affected. Born June 13, 1949. Third pregnancy (one girl, 4 years old, well; one stillbirth). No family history of pyloric stenosis. Parents not consanguineous.

Twin A. Girl. Birth weight $4 \mathrm{lb} .6 \mathrm{oz}$. Breast fed until onset of vomiting at 17 days. At 21 days she was admitted to hospital, a small, feeble and wasted infant weighing $3 \mathrm{lb}$. $6 \mathrm{oz}$. Peristalsis was seen and a pyloric tumour felt. At operation a typical pyloric tumour was found.

TwIN B. Girl. Birth weight $4 \mathrm{lb} .6 \mathrm{oz}$. Breast fed. Thrived and gained weight normally. There was an occasional small vomit during the second week of life, but no other symptoms. At 2 months of age she was examined during a feed, but no abnormality was discovered. No further investigations were carried out, but she was seen again at 6 months and was still free from symptoms.

\section{Discussion}

It is generally agreed that genetic factors play some part in the pathogenesis of pyloric stenosis, but their exact role is not understood. The problem has been discussed by Cockayne and Penrose (1943) who suggested that the incidence is determined by a recessive gene whose manifestation is influenced by birth order and sex. It is further considered by Carter and Savage elsewhere in this issue. A study of the occurrence of the condition in twins may contribute something towards the eventual solution of this problem.

Incidence of Pyloric Stenosis in Twins. Sheldon (1938) found 23 pairs among 1,000 cases of pyloric 
stenosis. One twin only was affected in each of 22 pairs, and in the remaining pair (the only one known to be monozygous) both were affected. There were therefore 24 affected twins among 1,000 cases, a ratio of 1 to $40 \cdot 7$. The incidence has been recorded in three other series. Ford et al. (1941) found 14 affected twins in 12 pairs among 436 cases, Monrad (1927) found three affected twins in three pairs among 228 cases, and Cockayne and Penrose (1943) found 13 affected twins in 11 pairs among 449 cases. If the four series are combined we get a total of 54 affected twins in 49 pairs among 2,113 cases of pyloric stenosis, a ratio of 1 twin to $38 \cdot 1$ babies born singly.

Laubscher and Smith (1947) pointed out that if there is one twin birth for every 80 single births, there are two twin babies for every 82 babies born, i.e. 1 in 41 , or a ratio of 1 to 40 . This is practically the same as the ratio of twins to babies born singly among the affected babies. In other words, the incidence of pyloric stenosis is the same in twins as in infants born singly. It is not twice as great as had been suggested by previous writers.

Occurrence in Monozygous Twins. Adding our cases to those previously reported (excluding those of Lasch as uncertain), we find that out of 17 monozygous pairs there are five in which only one twin was affected. The difficulty of determining the type of twinning with certainty has been stressed in this paper, but the evidence in these five pairs is in favour of monozygosity. Sheldon's pair had one placenta without any line of fusion and one set of membranes; the appearance of the twins was exactly the same; the finger-prints were not identical, but this has little significance. His account leaves little doubt that the twins were monozygous. Garrison's pair of negro twin girls had a single chorion and two amnions. A comparison of physical measurements at 20 months showed slight differences only, and a photograph of the twins at that age demonstrates great similarity of appearance. Detailed evidence of the type of twinning of the three pairs reported in this paper is given in the appendix.

There is no doubt that the diagnosis of pyloric stenosis was correct in the affected twins of the five pairs, for each case was confirmed at operation. The possibility must, however, be considered that the unaffected twin of each pair had hypertrophy of the pylorus without symptoms. Sheldon mentioned this, but in the absence of either symptoms or signs considered it unlikely in his case. Garrison considered that his unaffected twin might have fallen into this category. There were no symptoms, but he makes no mention of clinical examination or other investigation. In our three pairs the unaffected twins were examined with this possibility in mind, but no evidence of pyloric hypertrophy could be demonstrated. (In family 4 the unaffected twin was not seen until 2 months old, but one would expect a tumour, if present, to persist until this age.) It is interesting that Lewis's (1944) asymptomatic case was one of monozygous twins, the other one having manifest pyloric stenosis.

To sum up, there are at least five published pairs of twins, which can be accepted as monozygous, in which only one twin was affected. It therefore seems that the rule that both are usually affected does not hold good. It is not suggested that five out of 17 represents the true proportion of discordant monozygous pairs, for these are more likely to arouse interest and be reported.

Whatever part genetic factors play in the pathogenesis of pyloric stenosis, monozygous twins must be equally affected. To find a considerable number of monozygous pairs with only one twin affected is therefore surprising. It can be explained in one of two ways. The unaffected twin may in fact have hypertrophy of the pylorus but remain symptomfree. In this case the conditions (presumably postnatal) necessary for the development of symptoms must be present in one twin and not the other. It is known that asymptomatic cases do occur, but we were unable to discover any evidence of pyloric hypertrophy in any of our unaffected twins. This leads us to favour the alternative explanation, which is that one twin remains normal while the other is affected. If this is so, the development of pyloric stenosis must depend in part on the presence of an environmental factor which can act on one twin and not the other. This could be either prenatal or postnatal.

Occurrence in Dizygous Twins. Adding our case to those previously published, we find both twins affected in three out of 29 dizygous pairs. From a genetic point of view dizygous twins stand in the same relation to each other as ordinary siblings. Cockayne and Penrose (1943) found a definite familial incidence, which they put at 1 in 20 . We might expect therefore to find that a small proportion of dizygous twins is concordant. Three out of 29 is probably rather a high proportion, but concordant pairs are more likely to be reported.

The number of pairs of twins published so far is comparatively small, and before any final statement can be made about them many more will have to be studied.

\section{Summary}

Four pairs of twins affected by pyloric stenosis are reported. Three were monozygous with one of each pair affected. One was dizygous with both twins affected. 
Including these cases, there have been published in the literature 17 monozygous pairs of which five had only one twin affected, and 29 dizygous pairs of which three had both affected. Figures are quoted which show that the incidence of pyloric stenosis is the same in twins as in infants born singly.

Some points concerning the diagnosis of pyloric stenosis and the determination of the type of twinning are considered. The latter is further discussed in an appendix.

\section{A P P E N D I X}

There is no difficulty in classing twins as dizygous when they are of opposite sex, but the correct classification of twins of the same sex may not be easy.

The state of the membranes does not help much since about a third of monozygous twins are dichorial (von Verschuer, 1939). Probably the only definite conclusion that can be drawn from the state of the membranes is that in those cases where there is anastomosis between the circulations in the placenta, or only a single chorion can be demonstrated microscopically, the twins are monozygous.

Physical examination of the twins is usually more helpful, but it is easier to come to definite conchusions from such an examination in older children than in infants. Though monozygous twins will

TARue 1

Distribution of Characters in the Four familites

\begin{tabular}{|c|c|c|c|c|c|}
\hline & & Family 1 & Family 2 & Family 3 & Family 4 \\
\hline \multirow[t]{3}{*}{$\begin{array}{l}\text { Blood } \\
\text { Group }\end{array}$} & $\begin{array}{l}\text { Twin } 1 \\
\text { Twin } 2\end{array}$ & $\begin{array}{ccc}\text { Al CDoode. } & \text { MsMs. } \\
\text { Al } & \begin{array}{c}\text { Kell-.pp. } \\
\text { CDoode. }\end{array} \\
\text { Kell-. pp. }\end{array}$ & $\begin{array}{l}\text { A. D. MN. } \\
\text { A.D. } \mathbf{M N} \text {. }\end{array}$ & $\begin{array}{l}\text { O. cdecde. MSNs. Kell-. } \\
\text { pp. Lu- } \\
\text { O. CDeode. MsNs. } \\
\text { Kell-. pp. Lu-. }\end{array}$ & $\begin{array}{l}\text { O. CDecde. NsNs. } \\
\text { Kell-.pp. Lu (a+). } \\
\text { O. CDecde. NsNs. } \\
\text { Kell-. pp. Lu (a+) }\end{array}$ \\
\hline & Father & $\begin{array}{l}\text { codeode. MsMs. } \\
\text { Kedl-. Pp. }\end{array}$ & o. D. MN. & $\begin{array}{l}\text { O. colocde. NsNs. } \\
\text { Kell-. Pp. Lu-. }\end{array}$ & $\begin{array}{l}\text { A1. cDEode. NsNs. } \\
\text { Kell-. pp. Lu }(a+) .\end{array}$ \\
\hline & Mother & $\begin{array}{l}\text { Al CDeCDe. MsNs. } \\
\text { Kell-. pp. }\end{array}$ & A.D. MN. & $\begin{array}{l}\text { O. CDecde. MSMs. } \\
\text { Kell-. pp. Lu-. }\end{array}$ & $\begin{array}{l}\text { O. CDeCDe. MsNs. } \\
\text { Kell-.Pp. Lu. (a-). }\end{array}$ \\
\hline Hair & $\begin{array}{l}\text { Twin } 1 \\
\text { Twin } 2 \\
\text { Father } \\
\text { Mother }\end{array}$ & $\begin{array}{l}\text { Light rod-brown } \\
\text { Light red-brown } \\
\text { Dart brown (roddish as } \\
\text { a boy) } \\
\text { Light brown (no red) }\end{array}$ & $\begin{array}{l}\text { Light brown } \\
\text { Light brown } \\
\text { Black (since } \\
\text { infancy) } \\
\text { Brown }\end{array}$ & $\begin{array}{l}\text { Fair, curly } \\
\text { Fair, curly } \\
\text { Dark red-brown, curly } \\
\text { Medium brown, curly }\end{array}$ & $\begin{array}{l}\text { Light red, wavy } \\
\text { Light rod, wavy } \\
\text { Dark brown, wavy } \\
\text { Light red, straight }\end{array}$ \\
\hline Eyes & $\begin{array}{l}\text { Twin 1 } \\
\text { Twin 2 } \\
\text { Father } \\
\text { Mother }\end{array}$ & $\begin{array}{l}\text { Blue } \\
\text { Blue } \\
\text { Hazel } \\
\text { Green }\end{array}$ & $\begin{array}{l}\text { Dark blue } \\
\text { Dark blue } \\
\text { Brown } \\
\text { Brown }\end{array}$ & $\begin{array}{l}\text { Blue-grey } \\
\text { Blue-grey } \\
\text { Brown } \\
\text { Bluo-grey }\end{array}$ & $\begin{array}{l}\text { Blue-grey } \\
\text { Blue-grey } \\
\text { Hazel } \\
\text { Red-brown }\end{array}$ \\
\hline $\begin{array}{l}\text { Nail } \\
\text { Shape }\end{array}$ & $\begin{array}{l}\text { Twin } 1 \\
\text { Twin } 2 \\
\text { Father } \\
\text { Mother }\end{array}$ & $\begin{array}{l}\text { Broad } \\
\text { Broad } \\
\text { Broad } \\
\text { Long }\end{array}$ & $\begin{array}{l}\text { Long } \\
\text { Long } \\
\text { Long } \\
\text { Long }\end{array}$ & $\begin{array}{l}\text { Broad, square } \\
\text { Broad, triangular } \\
\text { Modium } \\
\text { Broad, square }\end{array}$ & $\begin{array}{l}\text { Long } \\
\text { Long } \\
\text { Long } \\
\text { Broad }\end{array}$ \\
\hline $\begin{array}{l}\text { Ear } \\
\text { Lobe }\end{array}$ & $\begin{array}{l}\text { Twin 1 } \\
\text { Twin } 2 \\
\text { Father } \\
\text { Mother }\end{array}$ & $\begin{array}{l}\text { Free } \\
\text { Free } \\
\text { Attached } \\
\text { Attached }\end{array}$ & $\begin{array}{l}\text { Attached } \\
\text { Attached } \\
\text { Attached } \\
\text { Free }\end{array}$ & $\begin{array}{l}\text { Free } \\
\text { Free } \\
\text { Attached } \\
\text { Attached }\end{array}$ & $\begin{array}{l}\text { Free } \\
\text { Free } \\
\text { Free } \\
\text { Attached }\end{array}$ \\
\hline $\begin{array}{l}\text { Frontal } \\
\text { Suture }\end{array}$ & $\begin{array}{l}\text { Twin } 1 \\
\text { Twin } 2 \\
\text { Father } \\
\text { Mother }\end{array}$ & $\begin{array}{l}\text { Keeled } \\
\text { Keeled } \\
\text { No ridge } \\
\text { Keeled }\end{array}$ & $\begin{array}{l}\text { No ridge } \\
\text { No ridge } \\
\text { No ridge } \\
\text { No ridge }\end{array}$ & $\begin{array}{l}\text { No ridge } \\
\text { No ridge } \\
\text { No ridge } \\
\text { No ridge }\end{array}$ & $\begin{array}{l}\text { No ridge } \\
\text { No ridge } \\
\text { No ridge } \\
\text { No ridge }\end{array}$ \\
\hline
\end{tabular}


ultimately have very similar skeletal measurements, this is not true at birth and in early infancy; where one twin is ill and malnourished such differences may be accentuated. Again differences in maturation make such criteria as hair colour and eye colour, characters which may change rapidly in infancy, less reliable than in adults. Finger prints and iris pattern are difficult to record and read in infancy.

The most valuable single characters are undoubtedly the blood groups. If the twins differ in any group they are dizygous. If they are the same for all groups, and the genotype of the parents blood groups is known, it is possible to give a figure for the probability that they are monozygous. The other characters listed in Table 1 are genetically determined, but the exact mechanism of inheritance is not known. For each of these characters in which the parents differ, resemblance of the twins increases the likelihood that they are monozygous, but no exact figures can be calculated for the probabilities involved.

Family 1. These twins were seen at 16 months of age. They resembled each other very closely indeed in body build, teeth pattern, and iris pattern as well as in the listed characters. While the blood groups do not provide strong evidence here (the odds are 3 to 1 on monozygosity) there is little doubt that they are monozygous. There was said to be one placenta.

Family 2. These twins were seen at 3 weeks of age. The death of one twin prevented any follow-up and complete investigation. The state of twinning must remain in doubt but it is more likely that they were monozygous than dizygous. From the MN blood groups the odds are 5 to 3 on monozygosity, and the hair colour adds some support. The doctor who delivered the twins reported that there was one placenta.

Family 3. These twins were seen at 5 weeks and again at 8 months of age. The blood groups make it certain that they are dizygous. When first seen the only obvious difference was in the nail-shape, but at 8 months the noses and mouths differed in size and shape, though the ears were still very much alike. The doctor who delivered them reported that there was one placenta with a line down the middle which he did not think indicated real cleavage.

Family 4. These twins were seen at 4 weeks and at 7 months of age. They are very probably monozygous. The odds from the blood groups are 31 to 1 on monozygosity, and there is supporting evidence from each of the characters listed. Twin 2 , the affected twin, was still $1 \mathrm{lb}$. lighter and $\frac{1}{2}$ in. shorter and had slightly fairer hair when seen for the second time. The doctor who delivered the twins reported that there was one placenta.

We are grateful to Dr. R. Lightwood, Dr. W. Sheldon, and Dr. W. G. Wyllie, for permission to publish these cases which were admitted under their care to The Hospital for Sick Children, Great Ormond Street, London.

We are much indebted to Dr. I. A. B. Cathie, Dr. R. R. Race, and Dr. S. D. Lawler, for determining the blood groups.

\section{REFERENCES}

Bexelius, G. (1939). Acta paediat., Stockh., 25, 22. Cockayne, E. A., and Penrose, L. S. (1943). Ohio J. Sci., $43,1$.

Davison, G. (1946). Archives of Disease in Childhood, 21, 113.

Ford, N., Brown, A., and McCreary, J. F. (1941). Amer. J. Dis. Child., 61, 41.

Findlay, L. (1937). Archives of Disease in Childhood 12, 399.

Garrison, R. F. (1949). J. Pediat., 35, 207.

Hughes, E. S. R., Small, H. A. D., and Macky, J. W. F. (1949). Brit. med. J., 2, 741.

Lamy, M., Pognan, C., Marillier, -., Jammet, J., and Cordier, P. A. (1949). Sem. Hôp. Paris, 25, 234.

Lasch, W. (1925). Munch. med. Wschr., 72, 1155.

Laubscher, J. H., and Smith, A. M. (1947). Amer. J. Dis. Child., 73, 334.

Lewis, F. L. K. (1944). Brit. med. J., 1, 221.

Malmberg, N. (1939). Nord. Med., 4, 3553.

Miller, R. F., and Ostrum, H. W. (1945). Amer. J. Roentgenol., 54, 17.

Monrad S. (1927). Mschr. Kinderheilk., 37, 473.

Olnick, H. M., and Weens, H. S. (1949). J. Pediat., 34,720 .

Sheldon, W. (1938). Lancet, 1, 1048.

Verschuer, O. von (1939). Proc. roy. Soc. B., 128, 62.

Wallgren, A. (1937). Svenska Läkartidn., 34, 635. (1946). Amer. J. Dis. Child., 72, 371.

Ward-McQuaid, J. N., and Porritt, B. E. (1950). Lancet, 1, 201 . 